\title{
CAPACIDADES DOS FORNECEDORES DE MÉDIO PORTE DA INDÚSTRIA NAVAL BRASILEIRA: O CASO DA MCM MONTAGENS INDUSTRIAIS
}

Marcos Primo ${ }^{1}$

Maria Lara ${ }^{1}$

Elidiane Melo Amaro ${ }^{1}$

${ }^{1}$ Universidade Federal de Pernambuco - UFPE 


\section{CAPACIDADES DOS FORNECEDORES DE MÉDIO PORTE DA INDÚSTRIA NAVAL BRASILEIRA: O CASO DA MCM MONTAGENS INDUSTRIAIS}

Resumo: A indústria de construção naval brasileira tem feito grandes investimentos nos últimos anos. Novos estaleiros buscam fornecedores que tenham qualidade e preço a níveis internacionais. Os fornecedores locais têm que investir em melhorias e inovações para poder competir com empresas estrangeiras. A limitação de recursos faz com que haja dúvidas sobre a capacidade de pequenos e médios fornecedores competirem nessa indústria. Um estudo de caso em um fornecedor de médio porte localizado em Pernambuco tenta identificar a capacidade de operações das empresas locais. Apesar das dificuldades, é possível para fornecedores de menor porte desenvolverem ações empreendedoras e atenderem as demandas dessa indústria, assim como se prepararem para mudanças que venham a ocorrer na mesma.

Palavras-chave: Capacidade de Operações. Inovação. Melhorias Operacionais. Ações Empreendedoras.

\section{Introdução}

A Indústria da Construção Naval (ICN) é caracterizada como uma indústria intensiva em mão de obra, apresentando grandes efeitos sobre a cadeia produtiva, especialmente a montante, ou seja, em relação aos fornecedores (Pasin, 2002). Weiss;Altmann, (2006) destacam a tendência de alto grau de terceirização na construção naval moderna, transformando a indústria naval em uma 'indústria montadora', o que contribui para o desenvolvimento de uma cadeia produtiva bastante diversificada. Assim, a nacionalização de parte da produção dos navios, com consequente desenvolvimento do setor produtivo naval no país, dependeria da capacidade operacional dos fornecedores nacionais em atender à construção naval $(\mathrm{CN})$.

Uma das dificuldades de estruturação da cadeia de suprimentos na ICN brasileira é que há defasagem entre a formação das expectativas de vendas, a encomenda de novos navios e a entrega dos mesmos aos armadores. Essa defasagem pode ser de alguns anos e favorecer o aparecimento de um grande hiato entre a oferta e a demanda de novos navios, o que afeta toda a cadeia produtiva (De Negri; Kubota; Turchi, 2009). Contribuindo para essa defasagem existe a instabilidade de demanda da ICN brasileira, a qual depende majoritariamente das decisões de compras da PETROBRAS. Essa instabilidade afeta a escala de produção dos fornecedores de peças para a ICN (navipeças).

O investimento em inovação e melhorias pelas empresas de navipeças brasileiras pode trazer um diferencial em longo prazo, além da possibilidade de consolidação da ICN nacional (Primo; Queiroz; Pinto, 2008). Nesse sentido, focalizaremos neste trabalho na inovação e
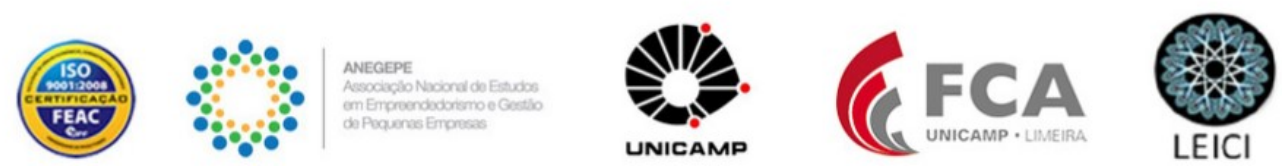
melhorias nos produtos e processos de fornecedores de pequeno e médio porte brasileiros para essa indústria no Brasil. Esse foco se dará sob a lente teórica das capacidades de operações desses fornecedores. As capacidades de operações envolvem elementos explícitos (recursos, práticas, etc.) e elementos tácitos (know-how, habilidades, liderança, etc.) para resolver problemas nos produtos e processos ou lidar com incertezas como as relacionadas com demanda. Essas capacidades, resultantes de combinações únicas desses elementos, são difíceis de identificar e, consequentemente, de imitar. Por isso, elas têm um papel estratégico no desenvolvimento da vantagem competitiva da organização(Grant,1991).

As capacidades de operações são habilidades, processos e rotinas da organização que configuram o sistema de gestão de operaçõesatendendo às necessidades da empresa. Em uma visão mais estática, apresentada como capacidades operacionais, proporcionam a competitividade atual da organização (Wu; Melnyk; Flynn, 2010). Em uma visão menos estática, apresentada como capacidades dinâmicas suportam mudanças nos atuais processos e rotinas, propiciando a competitividade futura da organização (Teece;Pisano;Shuen, 1997). De acordo com esses autores, as capacidades não são adquiridas facilmente, e devem ser construídas por meio de um processo de escolhas e trajetórias de longa duração, considerando o desenvolvimento de competências organizacionais

As capacidades de operações, especialmente as dinâmicas, têm sido crescentemente associadas com o comportamento empreendedor de uma organização (Meireles; Camargo, 2005). De fato, Teece;Pisano;Shuen, (1997) utilizam a perspectiva do empreendedorismo para definir os estágios de detecção, apropriação de oportunidades e reconfiguração organizacional no desenvolvimento das capacidades dinâmicas.Assim, o foco em capacidades, associado com melhorias e inovação, estaria associado com ações empreendedoras dessas empresas.

A literatura estabelece a importância de dois tipos de centrais de capacidades de operações: melhoria operacional e inovação operacional (Swink;Hegarty, 1998, Wu;Melnyk;Flynn, 2010). A melhoria operacional estaria relacionada à mudança incremental dos processos operacionais e produtos existentes, enquanto a inovação operacional refere-se à mudança radical dos mesmos ou a criação de novos processos e produtos. De fato, Patel;Terjesen; Li, (2012) apontam as capacidades de operações de acordo com mudanças incrementais (melhoria operacional) e mudanças radicais (inovação operacional) como direcionadores para o bom desempenho das organizações frente às incertezas do ambiente. Assim, faremos a análise das melhorias e inovações operacionais em fornecedores da ICN considerando suas capacidades de operações as quais estariam contempladas nas literaturas de capacidades operacionais e dinâmicas.

Em países em desenvolvimento, onde a inovação organizacional se dá em uma perspectiva mais incremental, a partir de aspectos relacionados à melhoria contínua e à análise de processos, as capacidades de operações podem estar associadas à participação das organizações na cadeia de suprimentos. No Brasil, estudos relacionados ao desenvolvimento de capacidades de operações de fornecedores pequenos e médios são escassos. Da mesma forma, investigações relacionadas à indústria de construção naval são incipientes e, normalmente, relacionadas às épocas anteriores de atuação da indústria no país, ou ao início do processo de retomada da construção naval Brasileira. Desse modo, esse artigo busca
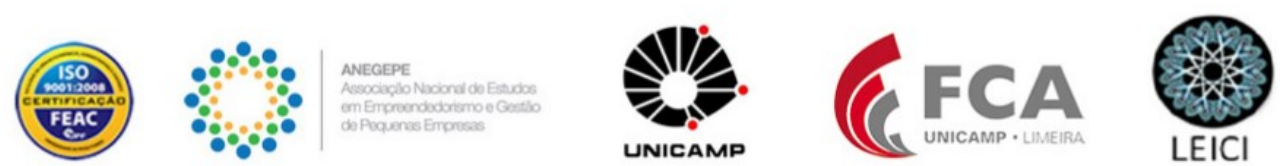
contribuir com esse debate ao analisar o desenvolvimento das capacidades de operações, focalizando ações de melhoria e inovação de um fornecedor de médio porte da ICN em Pernambuco; a MCM Montagens.

\section{Capacidades de Operações}

O termo capacidade, tradução de capability, refere-se à capacidade de fazer algo por meio do uso de competências e habilidades. As capacidades de uma organização podem lhe conferir vantagem competitiva sustentável e as capacidades de operações seriam um subconjunto das mesmas. Wu; Melnyk; Flynn, (2010) consideram esse subconjunto o 'ingrediente secreto' que explica a vantagem competitiva das organizações, diferenciando seus produtos dos de seus concorrentes, e, algumas vezes, passa despercebido, pois está enraizado na estrutura do sistema de operações.

Para Wu;Melnyk;Flynn, (2010), as capacidades de operações são particularmente difíceis de medir, porque surgem gradualmente e são tácitas, enraizadas, e se manifestam de formas diferentes entre as empresas, assim como são desenvolvidas com base em recursos, práticas operacionais, interação social, estrutura organizacional e cultura. As capacidades de operações envolvem elementos explícitos (recursos, práticas etc.) e elementos tácitos (know-how, habilidades, liderança etc.) no intuito de resolver problemas ou lidar com incertezas, gerando resultados compatíveis com as expectativas da empresa, sendo usadas como "meios" para atingir um "fim".

O enraizamento dessas capacidades de operações nas organizações é o resultado de três fatores: (1) a interligação das capacidades operacionais com os recursos e práticas operacionais; (2) as ligações entre as capacidades de operações e a rede social da organização; e (3) o ajuste com os principais problemas da empresa e a direção de sua gestão de operações. Esses fatores contribuem para que as capacidades operacionais sejam difíceis de replicar (Wu;Melnyk;Flynn, 2010).

Em sua pesquisa sobre a ligação das capacidades de operações e a diferenciação dos produtos de uma organização, Swink;Hegarty, (1998) classificam as capacidades de operações em estacionárias e em desenvolvimento. As capacidades de desenvolvimento, responsáveis pelas mudanças, são representadas principalmente pela Melhoria eInovação. De acordo com Peng; Schroeder;Shah, (2008) e Wu; Melnyk; Flynn, (2010), a melhoria operacional está associada ao conceito de exploitation e tem foco na mudança incremental, desenvolvendo novas formas de realizar as atividades a partir da modificação dos processos e reconfiguração dos recursos. A melhoria operacional pode ser identificada a partir das seguintes questões:

a) Os processos de produção são continuamente padronizados?

b) Os processos de produção são continuamente simplificados?

c) Os resíduos e as variâncias de processo são continuamente reduzidos?

d) O passado de sucessos e fracassos são utilizados para melhorar continuamente os processos?
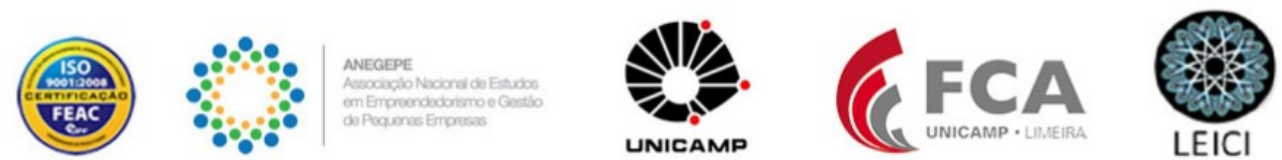
Ao contrário da mudança incremental, foco da melhoria operacional, a inovação operacional é utilizada para melhorar radicalmente os processos de operações já existentes ou criar e implementar processos novos e originais. Como se baseia em habilidades organizacionais existentes, a melhoria operacional dificilmente resultará em mudanças significativas das competências tecnológicas. Já a inovação operacional tem base na busca de variação e experimentação, a fim de mudar trajetórias tecnológicas e competências relacionadas $(\mathrm{Wu}$; Melnyk; Flynn, 2010).

A capacidade operacional de inovação busca mudanças radicais em grande escala, através de novos conhecimentos ou habilidades existentes, exigindo processos diferentes e reconfigurações de recursos, onde as mudanças incrementais não são suficientes. Associada ao conceito de exploration, a inovação operacional tem como foco habilidades, processos e rotinas relacionadas à busca, descoberta, experimentação e implementação (Wu; Melnyk; Flynn, 2010). A inovação operacional pode ser analisada por meio dos seguintes questionamentos:

a) Inovações desenvolvidas tornaram obsoletos os processos vigentes?

b) Inovações desenvolvidas mudaram fundamentalmente os processos prevalecentes?

Dada a importância da melhoria e inovação operacional na discussão anterior para as mudanças organizacionais, esse trabalho buscará identifica-las em um fornecedor de porte médio atuando em um cenário de incerteza da ICN brasileira.

\section{Procedimentos Metodológicos}

A pesquisa desenvolvida ao longo deste trabalho pode ser caracterizada como aplicada e exploratória. A forma escolhida para conduzir esta investigação foi o estudo de caso (Merriam, 1998; Miles;Huberman, 1994). Com base nesses dados, delimitamos como lócus da pesquisa, a empresa MCM, por se tratar de uma média empresa local, que se expandiu para atender outros estados.

Como sujeitos entrevistados foram escolhidos o diretor de operações e o gerente de projetos que a partir da visita de campo responderam a roteiro de entrevista semiestruturada em 44 mim e 101 mim respectivamente. Nessas ocasiões nos foi fraqueada o acesso às operações da empresa, o que nos permitiu várias observações. A partir dos relatos dos entrevistados, dos dados observados, e de documentos da empresa, identificamos elementos das capacidades operacionais de melhoria e inovação ratificando assim a característica qualitativa da pesquisa (Merriam,1998). A pesquisa de campo foi desenvolvida por meio da observação de fatos, visita em campo, e análise onde o ambiente natural foi uma das fontes de dados e entrevistas conforme Quadro 2 apresentado a seguir. 
Quadro 2 -Roteiro de entrevista semiestruturada.

\begin{tabular}{|c|c|}
\hline 1. & Breve Histórico \\
\hline 2.1 & Capacidade Operacional de Melhoria: \\
\hline \multicolumn{2}{|c|}{ Os processos de produção são continuamente padronizados? Existem programas de certificação? } \\
\hline \multicolumn{2}{|c|}{ Os processos de produção são continuamente simplificados? Melhoria de processos (eficiência) } \\
\hline \multicolumn{2}{|c|}{ De que forma os resíduos e as variâncias de processo são continuamente reduzidos? } \\
\hline \multicolumn{2}{|c|}{ O passado de sucessos e fracassos são utilizados para melhorar continuamente os processos? } \\
\hline \multicolumn{2}{|c|}{$\begin{array}{l}\text { Existem programas para refinar e reforçar os processos de operações existentes, de forma } \\
\text { incremental? Quais? Como são implementados? }\end{array}$} \\
\hline & Capacidade Operacional de Inovação: \\
\hline \multicolumn{2}{|c|}{$\begin{array}{l}\text { Existem melhorias radicais nos processos de operações existentes ou a criação de novos } \\
\text { processos? Como foi feito? Quais os novos processos? Inovações desenvolvidas tornaram os } \\
\text { processos vigentes obsoletos? }\end{array}$} \\
\hline & envolvidas mudaram fundamentalmente os processos prevalecentes? \\
\hline
\end{tabular}

\section{Fonte: Elaborado pelos autores.}

\section{Análise de resultados}

A MCM Montagens Industriais é uma empresa de engenharia com foco em soluções de montagem e manutenção eletromecânica industrial (MCM, 2016). Fundada em 1996, ela é oriunda do espírito empreendedor de um ex-integrante da empresa MONTECALM, que atualmente como a MCM, faz parte do Grupo Intercept. A empresa atua em todo o território nacional e presta serviços a diversos segmentos industriais, incluindo a ICN através dos estaleiros VardPromar e Atlântico Sul. A MCM é uma empresa familiar, com os cargos de presidência e direção (administrativo financeiro e operacional) ocupados por membros da mesma família, os quais detêm $30 \%$ do controle acionário da empresa.A participação no grupo Intercept, já consolidado no mercado, proporcionou à MCM agilidade em etapas cruciais na formação de estratégias de mercado, como investimentos em sistemas de gestão da qualidade e sistemas de gestão de projetos.

[...] No primeiro ano [de funcionamento a MCM] já começou a ficar independente. [...] O INTERCEPT é dono de 100\% MONTCALM e 70\% MCM. Os outros 30\% [da MCM] são dos diretores, porque o [presidente], que começou a empresa, trouxe os dois filhos, [...] um é diretor administrativo financeiro e o outro é diretor operacional, e eles também se tornaram sócios, $20 \%$ do [presidente] e $5 \%$ de cada um dos [...] dois diretores (MCM-GP).

A MCM possui um PMO (Project Management Office), que tem como objetivo melhorar cada vez mais o desempenho dos projetos executados pela empresa, promovendo o ciclo de atuação conforme metodologia do PMI (Project Management Institute). A Gestão da 
Qualidade é considerada uma das funções estratégicas da MCM, com foco na melhoria contínua dos seus processos e serviços, sendo geradora de valor para a empresa. A MCM tem seu Sistema de Gestão da Qualidade certificado na Norma NBR ISO 9001:2008, com foco em resultado, satisfação, melhoria e conhecimento. (MCM, 2016).

\title{
4.1 Fornecimento para a Indústria Naval
}

A MCM iniciou seu fornecimento à indústria naval a partir de projetos desenvolvidos com o estaleiro Navalmare, localizado em Recife-PE. "[...] Começamos lá no porto de Recife, na Navalmare. Fomos à Itália, aprendemos como eles montam lá e fizemos o treinamento" (MCM-GP). Atualmente a empresa possui contratos com os estaleiros Atlântico Sul e VardPromar.

\subsubsection{Fornecimento para o Estaleiro Atlântico Sul}

A relação de fornecimento entre a MCM e o estaleiro Atlântico Sul teve início através de uma montagem de máquina de pintura, onde a MCM atuou como fornecedor de segunda camada. Posteriormente, uma oportunidade de fornecimento direto se concretizou com a venda de spools para o estaleiro. Em seguida, a empresa participou da montagem de módulos para a plataforma P62, e atualmente está realizando a montagem de um transportador.

A experiência da MCM com contratos de prestação de serviço com o estaleiro Atlântico Sul, onde se fazia necessário desenvolver as atividades na planta do cliente, não apresentou resultados satisfatórios ao fornecedor. Em virtude da dependência de recursos do cliente, utilizados como insumos para os processos da MCM, sucessivos atrasos aconteceram e as dificuldades recorrentes levaram ao cancelamento do contrato.

\begin{abstract}
A [prestação de serviço in loco] atrapalha demais as operações do [fornecedor]. Totalmente. Aliás, um dos contratos que a gente tinha, que era com um consórcio com outro estaleiro, [...] foi difícil. [Atrapalhou] nossa ação comercial, porque tivemos que ir embora. [...] Todas as demandas de recurso eram deles. [...] Fechamos alguns contratos para [...] fornecer a mão de obra e para ele ficou todo o resto [...] guindastes, liberação de área, separar fornecimento, preparação de material, identificação, era tudo deles, do time deles e o que acontecia? O pessoal estava lá e eu não tinha como fazer nada (MCM-DO).
\end{abstract}

Já com o fornecimento de produtos, com o processo de fabricação sendo realizado na estrutura da MCM, os resultados foram positivos. Vale ressaltar nesse caso, mesmo com os problemas com a disponibilização de material por parte do estaleiro, a MCM conseguiu equilibrar seu processo produtivo e concluir as atividades.

\subsubsection{Fornecimento para o Estaleiro VardPromar}

A MCM começou a atuar como fornecedora de segunda camada para o estaleiro VardPromar. Posteriormente a empresa iniciou o fornecimento direto ao estaleiro.

Nós trabalhamos no Vard [Promar] junto com a Navalmare. Foi um consórcio [para montar módulos de embarcações] e a gente foi fornecedor, mas depois eles disseram

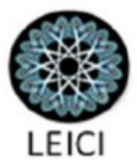


vamos fazer um consórcio e nós entramos como um consórcio para trabalhar para o Vard e aí ficou essa relação de fornecimento para o estaleiro.

Para o diretor de operações da MCM, a participação em um grupo já consolidado na indústria naval não foi suficiente para desenvolver aspectos de gestão no VardPromar. A estratégia de investir na captação de pessoas com experiência em outros estaleiros, no Brasil e no mundo, dificultou a integração desses recursos e o desenvolvimento estratégico da empresa.

\subsubsection{Considerações sobre o Relacionamento com a ICN}

Pela sua experiência de fornecimento na área naval, a MCM acredita que a seleção de fornecedores locais na ICN brasileira se dá, unicamente, com base no preço. Para o diretor operacional, esse critério pode mudar depois de algum tempo de relacionamento entre as empresas, mas é tratado caso a caso. A política de contratação centrada apenas no menor preço, de acordo com o gestor de operações, não é sustentável para os fornecedores, à medida que não permite uma análise justa do custo benefício e de condições adequadas de continuidade do empreendimento. Essa conjuntura acaba pondo em risco o próprio estaleiro, que contrata empresas sem condições de prestar o serviço adequadamente. Para o diretor de operações, os estaleiros ainda não realizam uma análise de critérios mais amplos na seleção de fornecedores e, dessa forma, acabam contemplando empresas sem condições adequadas para fornecimento.

[...] Existem algumas empresas que estão lá e não têm estrutura para trabalhar [...] eu não entendi porque elas estão lá. São empresas que não têm compromisso trabalhista, compromissos legais e eles (os estaleiros) valorizam isso. Se está lá trabalhando no meu ambiente, por mais que criem uma história retórica, [...] que o fornecedor tem que [...] qualificação, no fundo qualificação é meramente um documento que alguém cria. Mas sei que tiveram empresas que já foram expulsas de outro segmento [...] e estão lá, com um volume muito grande de gente, performando $[\ldots]$ no próprio estaleiro (MCM-DO).

\subsection{Capacidades Operacionais da MCM}

Essa seção busca identificar as capacidades operacionais da MCM. Para tal, buscou-se verificar a percepção dos entrevistados acerca das categorias da capacidade operacional, solicitando, sempre que possível, exemplos concretos para ilustrar a narrativa.

\subsubsection{Melhoria Operacional}

A MCM busca mostrar aos clientes sua infraestrutura, na perspectiva de que os mesmos possam verificar in loco cuidados que a empresa mantém com os seus colaboradores e com a qualidade dos seus processos organizacionais. Investimentos em equipamentos mais atualizados também é uma estratégia adotada pela MCM com o intuito de aumentar a qualidade de seus processos e produtos.

A MCM possui um Sistema de Gestão Integrado, certificado de acordo com as normas ISO 9001, ISO 14001 e OHSAS 18001 para Gestão da Qualidade, Meio Ambiente, Segurança e Saúde Ocupacional (MCM, 2016). E é certificada, desde 2003, no Certificado de Registro e Classificação Cadastral (CRCC) da Petrobrás.

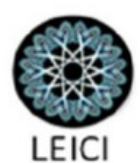


“[...] A gente consegue rapidamente se cadastrar [nos clientes] por ter as 3 [certificações] ISO. Tem cliente que se tiver ISO não precisa responder [...] porque a ISO já cobrou por ele" (MCM-GP).

A empresa possui uma cultura de verificação e revisão constante dos seus processos, principalmente por conta da certificação ISO, que exige revisão anual dos procedimentos. De acordo com o gerente de projetos, as auditorias internas, que são realizadas semestralmente, fornecem pontos de análise para melhorias, a partir das não conformidades identificadas.

Na perspectiva de deixar mais agradável o tratamento em relação às não conformidades, a empresa decidiu alterar a nomenclatura para registro de ação (RA). Além de ser emitida pelos auditores, o registro de ação também pode ser aberto pelo próprio funcionário para registrar ou alertar alguma alteração necessária em seu procedimento. Dessa forma, o registro pode ser analisado e desencadear alguma revisão no procedimento.Vale ressaltar que a quantidade de registros de ação que um colaborador recebe não afeta sua avaliação, desde que todos sejam respondidos no prazo. No entanto, caso não sejam respondidos, os registros afetarão a nota da auditoria, que compõe o prêmio semestral de participação nos resultados da empresa.

Quando nós criamos [o Mapeamento do Fluxo de Processos) aqui, chamamos todos os setores e [perguntamos]: - [...] dos seus produtos qual é o mais critico? qual é o que não pode deixar de fazer? A gente foi listando os produtos críticos, [que] geraram o fluxo critico e, através do fluxo crítico, depois nós geramos o plano de risco (MCM-GP).

O gerente de projetos ressalta, ainda, que inicialmente foi contratada uma consultoria para implementar o sistema de gestão, mas a relação não foi bem-sucedida. Dessa forma, optou-se por estruturar o sistema de gestão a partir de colaboradores que vivenciassem os processos e conhecessem bem a organização, de forma holística.

\section{[...] a MONTCALM [...] contratou uma consultoria [...] [que] passou uns 6 meses tentando padronizar. Cada setor fazia de um jeito e agora tem um produto, houve interação entre os setores e aquilo tudo foi muito bonito e foi muito importante porém, a pessoa não vivia a empresa e a gente via que ficava patinando, [destacando] coisas exageradas. [...] teve um embate grande porque o engenheiro dizia [que estava] muito exagerado, [que] não ia dar em nada, que [era] muito papel e ninguém iria conseguir fazer isso na obra. Teve um desgaste e a consultoria saiu [...] (MCM-GP).}

A MCM tem a prática de compartilhar experiências de sucesso e dificuldades entre os colaboradores, principalmente com a equipe que trabalha diretamente nas obras. Através de reuniões de abertura e encerramento das obras, atas são registradas com as principais informações e servem de insumo para análise de projetos posteriores. Relatórios de lições aprendidas também são postados mensalmente no sharepoint, para consolidação de informações, pelo gestor de projetos, e registro no sistema da organização.

Simulados de segurança do trabalho também são usados como fonte de análise para melhorias contínuas na organização. A partir de um simulado realizado no prédio central foi detectado a necessidade de alteração do layout da sala. "[A partir do resultado do simulado] teve que mudar essa porta aqui, ela era para o lado errado, abrimos outra porta em outro lugar porque

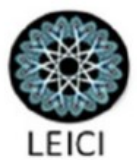


ficou muito distante para buscar ajuda, mas gerou melhoria" (MCM-GP). A preocupação com a melhoria nos aspectos de segurança também ficou evidente nos simulados previstos na ISO 18001.

Para realizar o fornecimento ao setor naval, a MCM não apresentou dificuldades relacionadas à qualidade de seus produtos ou precisou realizar melhorias em processos. De acordo com o diretor de operações, a certificação de soldagem, que é realizada pela sociedade classificadora e inerente à entrada de qualquer prestação de serviço de solda no estaleiro, foi o único requisito que a empresa precisou providenciar. "A única coisa que a gente precisou efetuar foi na parte de soldagem, na qualificação dos soldadores. Porque eles têm uma certificadora, [...] a $\mathrm{BV}$ ou $\mathrm{ABS}$, e você tem que seguir algumas exigências de qualificação do soldador [...]" (MCM-DO).

\subsubsection{Inovação Operacional}

A MCM considera pesquisa e inovação, valores estratégicos para a empresa. A partir do Departamento de Inovação e Tecnologia, a empresa busca se atualizar com a participação em eventos e mantem contato com departamentos semelhantes das outras empresas do grupo. A empresa também possui a carta técnica de inovação, um documento que é enviado ao cliente para informar todas as inovações que serão utilizadas nos processos. "Nós temos uma carta técnica de inovação, que é enviada para obra toda vez [...] e tudo que é novidade vai" (MCMGP).

A partir de dificuldades encontradas nos processos operacionais nas obras, o departamento de inovação busca desenvolver soluções adequadas para agilizar o desenvolvimento do processo produtivo. Na perspectiva de diminuir os obstáculos de tempo e mão de obra na construção dos canteiros de obras, o departamento desenvolveu um canteiro modulado, que pode ser montado em 4 horas e já oferece todo o suporte de infraestrutura necessário ao início dos procedimentos da obra. Dessa forma, um processo que demoraria, em média, 40 dias está sendo realizado em 1 dia.

A implantação de uma gestão voltada para o gerenciamento de projetos é apontada como uma estratégia de inovação da MCM. Como trabalha a partir de projetos, a empresa conseguiu padronizar sua atuação a partir da centralização da gestão de obras na CAC e, assim, conseguiu minimizar as disparidades de execução, que aconteciam entre um projeto e outro, criando um escritório de gerenciamento de projetos com os melhores profissionais de cada área.

Com a unificação da gestão de obras na CAC, acompanhada dos melhores profissionais nas áreas do projeto, a MCM conseguiu estabelecer um padrão único de desenvolvimento de projetos, adotando e disseminando as melhores práticas, que anteriormente eram realizadas pelos gestores das obras, individualmente. As mudanças sugeridas nos processos são avaliadas pela Central e, posteriormente, disseminadas igualmente em toda a empresa (todas as obras).

Um exemplo de inovação desenvolvido pela MCM é o processo de gerenciamento de arquivos físicos das obras. Os documentos eram enviados em caminhões à central de apoio e

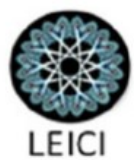


controle após a finalização das obras e, a partir de discussões e amadurecimento de propostas de melhoria, foi desenvolvido um processo de gerenciamento de arquivos no sistema da empresa. De acordo com as informações cadastradas no sistema, lembretes são enviados aos funcionários e chefias imediatas, na perspectiva de alertar sobre prazos ou ausências de documentos previstos. Esses alertas são solicitados pelo setor de qualidade no momento da realização de auditorias internas, no intuito de verificar se as solicitações foram atendidas. $\mathrm{O}$ Quadro 2 apresenta um resumo das capacidades de operações da MCM.

\begin{tabular}{|c|c|}
\hline $\begin{array}{l}\text { Capacidade } \\
\text { Operacional }\end{array}$ & $\mathrm{MCM}$ \\
\hline $\begin{array}{c}\text { Melhoria } \\
\text { Operacional }\end{array}$ & $\begin{array}{l}\text { Certificações ISO } \\
\text { Melhoria de produtos e processos } \\
\text { Melhoria de infraestrutura } \\
\text { Cultura de gestão da qualidade } \\
\text { Visão holística da organização }\end{array}$ \\
\hline $\begin{array}{c}\text { Inovação } \\
\text { Operacional }\end{array}$ & $\begin{array}{l}\text { Departamento de Inovação e Tecnologia: Canteiro, Payshop, } \\
\text { equipamentos de solda, etc. } \\
\text { Sistema de gestão de arquivos } \\
\text { Escritório de gerenciamento de projetos }\end{array}$ \\
\hline
\end{tabular}

Quadro 2 -Resumo das capacidades de operações da MCM (elaborado pelos autores)

\section{Considerações Finais}

O trabalho buscou identificar as capacidades de operações, especialmente as de melhoria e inovação em um fornecedor de porte médio da ICN no país. Apesar da literatura destacar a dificuldade de identificá-las, verificamos vários componentes dessas capacidades e a importância das mesmas para o sucesso daquela empresa. Dessa forma, este estudo responde à escassez de estudos relacionados ao desenvolvimento de capacidades de operações de fornecedores pequenos e médios na nossa ICN. Os resultados atestam que, apesar das limitações de recursos, fornecedores de menor porte podem desenvolver ações empreendedoras e atender às demandas dessa indústria, assim como se preparar para mudanças que venham a ocorrer na mesma.

\section{Referências}

DE NEGRI, J. A., KUBOTA, L. C., TURCHI, L., Inovação e a Indústria Naval, Associação Brasileira de Desenvolvimento Industrial (ABDI), 2009.

GRANT, R. M. The Resource-based Theory of Competitive Advantage: Implications of Strategy Formulation. California Management Review, p. 114 - 135, 1991.

MCM. Disponível em: <http://www.mcm.com.br > Acesso em fevereiro de 2017.

MEIRELlES, D. S.CAMARGO,A. A. B., Capacidades Dinâmicas: O Que São e Como Identificá-las? Revista de Administração Comtemporânea- $R A C$, Rio de Janeiro, v. 18, 
p. 41-64, Dezembro 2014.

MERRIAM, S. Qualitative research and case study applications in education. San Francisco: Jossey-Bass, 1998.

MILES, M. B.; HUBERMAN, A. M. Qualitative Data Analysis: an expanded sourcebook.2.ed. Thousand Oaks: SagePublications, 1994.PASIN, J. A. B. Indústria Naval do Brasil: Panorama, Desafios e Perspectivas. Revista do BNDES, Rio de Janeiro, v. 9, n. 18, p. 121-148, 2002.

PATEL, P C.; TERJESEN, S; LI, D. Enhancing effects of manufacturing flexibility through operational absorptive capacity and operational ambidexterity. Journal of Operations Management v. 30, n. 3, p. 201-220, mar. 2012.

PENG, D. X.; SCHROEDER, R. G.; SHAH, R. Linking routines to operations capabilities: A new perspective. Journal of operations management, v. 26, n. 6, p. 730-748, 2008.

PRIMO, M. A. M.; QUEIROZ, A. A. F. S. L.; PINTO, M. M. O. Aprendizagem Tecnológica no Fornecimento da Construção Naval Brasileira. In: XXXII ENANPAD Encontro Científico de Administração, 2008, Rio de Janeiro. Anais do XXXII ENANPAD. Rio de Janeiro, 2008.

SWINK, M.; HEGARTY, W H. Core manufacturing product differentiation. International Journal of Operations \& Production Management v. 18, p. 374 - 396, 1998.

TEECE, D. J.; PISANO, G.; SHUEN, A. Dynamic capabilities and strategic management. Strategic Management Journal, v.18, n.7, p. 509-533, 1997.

WEISS, J.; ALTMANN. Cadeia de Suprimentos e Competitividade da Indústria de Construção Naval. Instituto de Pesquisas tecnológicas, São Paulo, 2006.

WU, S. J.; MELNYK, S. A.; FLYNN; B. B. Operationalcapabilities: thesecretingredient. Decision Sciences, v. 41, n. 4, p. 721-754, 2010. 
